\title{
Research on Cultivation of Excellent Talents in Major Class
}

\author{
Shi-Baoyu \\ School of Economy and Management \\ Qiqihar University \\ Qiqihar, Heilongjiang, China \\ Sby370@126.com
}

\author{
Liu-Jingjun \\ School of Economy and Management \\ Qiqihar University \\ Qiqihar, Heilongjiang, China
}

\begin{abstract}
Talents with Innovation and entrepreneurship are currently meeting mainstream of social needs, forcing some adjustments in talent cultivation in colleges. The admission by major class is a new type of talent training mode put forward by general education concept. On the basis of analyzing the advantages of admission by major class, this paper proposes ways to optimize and cultivate outstanding talents from the aspects of training schemes, cultivating modes, ability practices and the second-class activities. Then the paper develops a practical management mechanism to ensure effective personnel training system.
\end{abstract}

Keywords-Outstanding talents; Admission by major class; Ways of cultivating; Innovation

\section{INTRODUCTION}

Institutions of higher learning are the places to innovate knowledge and train advanced professional talents, shouldering heavy responsibility of social developing. With the rapid development of knowledge and information society, colleges and universities are facing greater challenges for all kinds of institutions of higher learning as well as opportunities for development. In the 'Outlines of Long-term Education Reform and Development (2010-2020)', the Ministry of National Education explicitly put forward the core meaning of 'Excellent Talents Training Plan", pointing out the direction for the reform and development of colleges and universities is putting the development of connotation in top priority 1 . In recent years, all kinds of colleges and universities have carried out attempts to reform their personnel-training mode according to the needs of social development. Many colleges and universities have adopted this new type of personnel training mode. The 'Excellent Talents Training Plan' that born at right time also showed a slightly effect.

\section{ADVANTAGES}

\section{A. Avoid blindness and enhance the plan}

According to the survey of the majors chosen by first-year students, nearly $60 \%$ of college students follow their parents and teachers' advice or obey the regulation and transfer to the current majors. If schools offer students a second chance, nearly $50 \%$ of the students will re-consider their choices on major selection2. Therefore, the 'Admission by major class'

\footnotetext{
1. Fund project: Heilongjiang province philosophy and social science

research planning project (15EDE12C):

2. Heilongjiang Provincial Institute of higher Education Project (16G245)

3. Qiqihar University Education Project (2016061)
}

talent training mode constantly consolidate professional basic courses in the first one or two years, developing further interest in learning for the next step according to individual characteristics and development needs of the professional direction choices. Not only does it avoids the blindness, but cultivates students self-planning and self-management capabilities at the same time as well.

\section{B. Avoid relaxation and enhance competition}

Students who pass through arduous college entrance examination, break free from their parents and become a temporary independent social individual will inevitably have the intention to soar to greater heights. The concept of 'One Test and for All' leads students to slack thoughts, ignoring the professional courses in the colorful life in college. After they wake up from such a soaring freedom, their college lives are nearing a completion as well. 'Admission by major class' can better realize 'thicker foundation and wider caliber'. Professional diversion could be achieved by comprehensively combining the academic achievements of the students in the first one or two years, enabling students to face up their own learning purposes after entering the school, enhance learning motivations and competition awareness, which will benefit the universal improvement of the quality of personnel training.

\section{Avoid restrictions and enhance interaction}

In modern society, science and technology is developing increasingly. The key to focusing on the good momentum of national development is the number of talents. High-level versatile, application-oriented elite-talent is the focus of competition. Therefore, there is an increasing demand from the society and the market for "versatile talents" who have a solid foundation, extensive knowledge and strong adaptability. Individual students who want to meet the needs of the community talent must choose their own characteristics to match the paths of development3. 'Admission by major class' starts an effective and reasonable classified-training according to the characteristics and the needs of developments of individual students. It gives a full play to the candidate's own personality, guarantees the latter part of professional courses in a more scientific and reasonable way. Talents use a two-way interactive mode to better improve the adaptability of students. 


\section{B. Various forms of training mode is the means}

The scientific talent training program laid the foundation for the cultivation of "outstanding talents", and clarified the target system and content system of personnel training. But the more important thing is to complete the process of training personnel which is the teaching process. Through the development of strict management system and security system, teaching process gets its best effect. Through practical research, professional characteristics should be fully considered in the cultivation of "outstanding talents" and different training models should be constructed.

\section{1) 3+1 Teaching Mode}

This teaching mode breaks the barriers of 'teaching' and 'learning' of the four-year system of teachers and students and pays more attention to strengthening students' practical ability, allowing graduates to have more ability to operate and think. The teaching effect of most colleges and universities is not obvious. It takes a long time for the students to get employed and can adapt to their posts. Therefore, $3+1$ teaching mode has become the focus of talent training reform. With the goal of 'laying a solid foundation, strengthening professionalism, attaching importance to practice, improving quality and ensuring employment', we will conduct internship practice and graduation design in the fourth year. For example, the educational internship of the whole year of education will pull practical classrooms to primary and secondary schools so that students can practice their exercises in the classroom. The musical performances can perform rehearsals of original works, participate in large-scale performances and rehearsals. Teachers give proper guidance and give full play to students' practical ability to achieve the theory and practice of harmony and unity.

\section{2) Internship mode}

This model is based on the market demand for the training of personnel mode. Through the establishment of an internship base, regular internship opportunities are provided to students every year. Regular meetings of talent supply and demand will be held to introduce the job market into schools so that students have the opportunity to practice in designated enterprises and institutions. Through the admission by major class, compact teaching plan, solid basic knowledge teaching, using the first two to three years before the completion of undergraduate fulltime teaching plan, master the solid basic knowledge and basic skills, take full advantage of the last school year's holidays and after-hours. Using 'prospective employees' status in the real business environment for job training4. Let students fully understand the similarities and differences between the theoretical teaching and business practice in schools, quickly adjust to meet the needs of society, the school give full play to the advantages of theoretical guidance, and enterprises play practical training advantages. We put forward the authenticity and operational tasks to the students through the enterprises. Supplemented by the practical guidance of the technical staff, students' awareness of staff and responsibility to improve and enhance the ability of students' entrepreneurship. 


\section{3) School-Enterprises cooperating mode}

Schools and businesses co-cultivate talent, which is a direct "customized production" training mode in accordance with business needs. Industries themselves have become the makers of educational content and standards, with schools as implementers and nurturing talent by referencing business needs. The philosophy of this teaching model is learningworking-learning-working-learning in a cycle. The main teaching places are also extended from the classroom to the training workshop, the workplace, fully reflect the individual teaching, combining the work experience with the overall teaching. Classroom are set to simulate a real work environment, but also in the workplace of the enterprise teaching. Through a combination of work experience, finally returned to school to complete the graduation project. Enterprises can cultivate basic employees according to their own culture and enhance employee loyalty. Such customized personnel training mode of school-enterprise cooperation can better meet the needs of local economic development and achieve "seamless" school-based docking5.

\section{4) A total research model by teachers and students}

This is a teacher-led, student-mentored tutor-training model. 'Outstanding personnel training' focuses on talents. Talent reflects on 'excellence'. Therefore, we plan to find high quality, strong-based, practicing and thinking-loving students in our school's students to carry out advanced training, mentoring training system. The teachers open their own scientific research activities and scientific research contents that are closely related to the personnel training to students who have some basic scientific research tasks. Through the proposed tasks and problems, to promote students access to information, brain thinking, summarize, put forward this series of questions. The teacher guides the student to carry on the practice, and gradually guides the student to participate in the research depth and the breadth of the subject according to the student completes the situation. By teachers and students together, teachers, students participate in the common practice of teaching outside. This mode of cultivation strengthens the exchange and interaction between teachers and students, enhances students 'questing abilities, arouses students' interest in learning and better translates the skills taught by teachers into the personal experience and wisdom of students. Currently colleges and universities have adopted "flip the classroom" to achieve the promotion of this teaching mode, the future will surely become the main teaching mode of research universities.

\section{Innovation and entrepreneurship training of college students is a carrier}

The cultivation of "outstanding talent" not only requires a scientific talent training model, but also requires a broader platform for students to expand their capabilities in order to improve the overall quality of students. In addition to increase the practical teaching design within the teaching plan, students should also be urged to make full use of their spare time for capacity training and avoid making decisions only on paper. For example, at present, colleges and universities are to create innovative and entrepreneurial guidance for college students. They provide financial support for innovation and entrepreneurship training of students with subjects covered in social, economic, cultural, political, educational, ecological and other fields, so that students from their own interests, close contact Professional knowledge, designed to guide students to actively self-learning, self-practice, self-innovation ability training6. Through independent scientific research and investigation reports, under the guidance of teachers, a task report or profit-making entity with a certain technical content and value is formed. These are the hot issues in society or from the teacher research sub-project, or internship base, a comprehensive experimental laboratory project has a strong real value, practical and a certain amount of promotional value, as becoming an 'outstanding talent' platform for training.

\section{Abundant after-class activities are indemnify}

The cultivation of 'outstanding talent' is a long-term systematic project that requires the common exploration and practice of teachers and students. The main learning place for students is the school. Therefore, building a second class activity with characteristics, rich content and connotation is the guarantee of cultivating 'outstanding talents' and becoming the cultural nourishment for the cultivation of 'outstanding talents', which can help students form a positive and progressive style of study, enhance student cohesion. The school introduces the cutting-edge knowledge of the subject to the campus by carrying out lectures on academic exchanges both at home and abroad so as to bring it in line with advanced institutions and expand students' horizons. Through various kinds of campus culture such as skill competitions, campus culture festivals and campus science festivals to stimulate student enthusiasm for learning; encourage students to participate in all competitions at all levels, enhance students' sense of competition, and learn from the precious experience of practice. 


\section{OVERALL IMPROVEMENT OF MANAGEMENT MECHANISM}

The cultivation of 'excellent talents' came into being under the background of admission by major class, which was a good start but an integrated system constrained by students, teachers and employers. In addition, the school curriculum system, the allocation of hours, teacher resources, credit requirements, organizational structure, management mode and other factors also affect the effectiveness of such personnel training. With the gradual deepening of the cultivation of 'outstanding talents', all colleges and universities need to establish and improve the operation and management mechanism that accompanies them, so as to effectively improve the quality of personnel training.

\section{A. Organizations need collaboration}

The cultivation of 'outstanding talents' requires the concerted efforts of the school admissions office, the academic office, the practice office, the second-level college, various professions, departments and other organizations to start from the freshmen until graduation is a dynamic management process. Every aspect is crucial, so all departments work methods, work attitude, work efficiency requires clear requirements. Not only need division of labor, but also cooperation, interlocking, to establish a reasonable operation and management mechanism, and strictly enforced, conducive to the implementation of the training of 'outstanding personnel', play the role of guidance, inspection, evaluation and supervision, so that all departments can collaborate on working.

\section{B. Training program "rolling" management}

At this stage, the vast majority of university personnel training programs strictly implement the credit system, public basic courses and the total credits according to the country's requirements is difficult to change, talent training program, but revised, to use a cycle, to revising the problem can be adjusted to change. In the days when higher education has become more and more popular, the revised mode of personnel training programs meets the training needs of individualized students. The restrictions on credit hours and credits have also become the resistance factor in practice teaching. In response to this factor, schools should formulate a 'rolling' plan revision mode according to the development of society and demand. Flexible management should be implied in teaching management and make timely adjustments according to the feedback from the personnel training process. It will not lose the opportunities for reform of personnel training because of the revision of personnel training programs every four years, thus resulting in the loss of employment competitiveness of students.

\section{Building teachers team with high levels}

The training of 'outstanding talents' aims to train solid professionals with strong basic knowledge, practical ability and high comprehensive quality, which puts forward higher requirements on the teaching staff and teaching management in colleges and universities. Teachers should have a high level of scientific research, a rigorous academic attitude, and the guidance and guidance of students in conducting research and practical operations while ensuring the teaching level. Therefore, the school needs a 'double-division type' teacher team. In the classroom as a teacher preacher, in practice as a senior engineer, technician identity demonstration guide. Conducting 'theoretical teaching' and 'demonstration' in such a free conversion. 'Double-qualified' teaching team cannot be accomplished in one fell swoop. Schools can also employ 'professional mentors' to solve this problem by engaging various technical professionals working in various fields in practical teaching so as to ensure that students' practical teaching can truly achieve the desired teaching effect7.

\section{School-enterprise cooperation model}

Enterprises with advanced production equipment, a wide field of rooms and experienced production technicians, the school laboratories are difficult to match comprehensively. At this stage, the cooperation between school and enterprise only stays in the agreement of the training base construction, and the internship process is sometimes mere formality. Once the personnel of the organization change, the cooperation relationship will be affected. Therefore, how to form a one-stop, win-win cooperation model of production, study and research is worth discussing8. Enterprises are for profit for the purpose of naturally need profitable, schools and enterprises should jointly conduct horizontal scientific research projects to declare to strengthen teachers and researchers to contact, as much as possible to provide services to enterprises, provide technical support, and through the practice of students Activity for the enterprise to create profits. Clear their respective tasks and division of labor in personnel training to develop a variety of operational training plan, and in accordance with the demand for timely adjustment, together with infiltration.

\section{E. Teaching management with full monitoring}

The process of cultivating 'outstanding talents' is a process of reform and exploration. To ensure the effectiveness of the reform, there must be an appropriate management system in place. It also needs teaching supervision and inspection, monitoring. Correct feedback and evaluation, in the teaching process, through lectures, spot checks homework, and practical information to find the problems in both theoretical teaching and practical teaching. Through holding teachers and students' symposiums, we can solve the problems raised by the students, assess the teachers' teaching ability and students' satisfaction through teaching evaluation and questionnaires, and summarize the feedbacks to teachers. Therefore, finally achieve the teaching of the 'four in one' full monitoring. 


\section{F. Reasonable Investment of Teaching Funds}

Reasonable funding for personnel training to ensure the rationality and safety of funds used to improve the efficiency of the use of funds, there must be a clear and procedural system of use of teaching expenses. Do a good job in the annual budget, save unnecessary expenses, earmarked, sub-priority funding, and ensure efficient feedback capabilities, so that 'every cent is spent on the knife.'

\section{CONCLUSION}

To sum up, the cultivation of "outstanding talents" under the category of "big class enrollment" is a major reform in China's education system, a requirement of the country's scientific development, a need of the future talent market for the society, and a need of competition in running a university. In order to highlight outstanding features in talent cultivation, we must formulate purposeful development plans according to the conditions we have, and in accordance with the characteristics and needs of local economic development at the same time. All the departments should fully cooperate, follow the plan steadily, and accumulate experience in practice so that 'outstanding talents' can be cultivated at every university and universities. This will help boost the development of the country's economy.

\section{REFERENCES}

[1] [Ministry of Education's Opinion on Implementing a Program of Education and Training for Engineers of Excellence [[EB / OL].

[2] http://www.moe.gov.cn/publicfiles/business/htmlfiles/moe/s3860/20110 2/115066.htm1.

[3] Chang Jifeng, Pan Rui. Excellence in school-enterprise cooperation model of sustainable development [J] Heilongjiang Higher Education Research, 2012 (11). 122.

[4] Wang Aixia, Luo Dejun. "Excellent Engineer (Software)" schoolenterprise cooperation education and training mode $[\mathrm{J}]$ Science and Education Department, 2015 (10).73-74.

[5] Zhang Wensheng, Song Kairu. Reflections on the Implementation of "Excellent Engineer Education and Training Plan" under the Concept of "Return to Engineering", Journal of Northwestern Poly technical University, 2016 (1). 82.

[6] Daiyuchun. Discussion and thinking on the development of the production and research of local engineering colleges [J]. China higher education,2016 (09), 68-69.

[7] Ningjing. Comparative study on the model of industry-universityresearch alliance [D]. beijing:bejing Jiaotong University.2015(5).87-89.

[8] Lidapeng. Cooperation on industry-university-research and the cultivation of innovative talents [J]. Exploration of higher education, 2014 (7) 46-47. 